\title{
Facile In Situ Fabrication of Nanostructured Graphene-CuO Hybrid with Hydrogen Sulfide Removal Capacity
}

\author{
Sunil P. Lonkar ${ }^{1} \cdot$ Vishnu V. Pillai $^{1} \cdot$ Samuel Stephen $^{1} \cdot$ Ahmed Abdala $^{1} \cdot$ Vikas Mittal $^{1}$
}

Received: 20 December 2015/Accepted: 8 March 2016/Published online: 23 March 2016

(C) The Author(s) 2016. This article is published with open access at Springerlink.com

\begin{abstract}
A simple and scalable synthetic approach for one-step synthesis of graphene-CuO (TRGC) nanocomposite by an in situ thermo-annealing method has been developed. Using graphene oxide (GO) and copper hydroxide as a precursors reagent, the reduction of $\mathrm{GO}$ and the uniform deposition of in situ formed $\mathrm{CuO}$ nanoparticles on graphene was simultaneously achieved. The method employed no solvents, toxic-reducing agents, or organic modifiers. The resulting nanostructured hybrid exhibited improved $\mathrm{H}_{2} \mathrm{~S}$ sorption capacity of $1.5 \mathrm{mmol} \mathrm{H}_{2} \mathrm{~S} / \mathrm{g}$-sorbent ( $3 \mathrm{~g} \mathrm{~S} / 100 \mathrm{~g}$-sorbent). Due to its highly dispersed sub-20 $\mathrm{nm} \mathrm{CuO} \mathrm{nanoparticles} \mathrm{and} \mathrm{large} \mathrm{specific} \mathrm{surface} \mathrm{area,} \mathrm{TRGC} \mathrm{nanocomposite} \mathrm{exhibits} \mathrm{tremendous}$ potential for energy and environment applications.
\end{abstract}

Keywords $\mathrm{CuO} / \mathrm{graphene} \cdot$ Adsorption $\cdot$ Breakthrough capacity $\cdot$ Hydrogen sulfide $\cdot$ Thermal stability $\cdot$ In situ synthesis

\section{Introduction}

The combination of multidimensional nanomaterials often leads to the formation of hierarchical and multifunctional materials that combine the advantages of each component, thus, resulting in exceptional properties. Recently, composites of graphene with various inorganic nanostructures including copper oxide $(\mathrm{CuO})$ have attracted a great deal of interest due to synergistic combination of properties and potential applications [1-3]. In general, it is believed that incorporation of multidimensional inorganic particles may prevent the aggregation of graphene sheets with higher surface area and pore volume. Similarly, the graphene sheets can effectively stabilize inorganic nanoparticles to prevent their aggregation, and the properties of the nanoparticles could be enhanced through anchoring them onto graphene sheets [4-6]. Graphene, the 2-D $s p^{2}$ network of carbon atoms possesses several intriguing and peculiar

Vikas Mittal

vmittal@pi.ac.ae

1 Department of Chemical Engineering, The Petroleum Institute, Abu Dhabi, United Arab Emirates properties such as high charge mobility $\left[100,000 \mathrm{~cm}^{2}\right.$ $(\mathrm{V} \mathrm{s})^{-1}$ ], high surface area $\left(2630 \mathrm{~m}^{2} \mathrm{~g}^{-1}\right)$, thermal conductivity (2000-5000 $\mathrm{Wm} \mathrm{K}^{-1}$ ), and optical properties [7]. On the other hand, $\mathrm{CuO}$, an important $p$-type transitionmetal oxide with a narrow band gap $\left(E_{\mathrm{g}}=1.2 \mathrm{eV}\right)$ and excellent chemical stabilities, has been investigated extensively for active anode materials, superconductors, sensors, and heterogeneous catalysts. It is also a promising material for fabricating solar cells, due to its photoconductive and photochemical properties [8-10]. Hence, hybridization of these two materials leads to nanohybrids of graphene and $\mathrm{CuO}$ with outstanding properties suitable for a variety of applications such as sensors [11-13], photocatalysis [14], water treatment [15], energy storage $[16,17]$, etc.

Several approaches have been proposed for preparing nanostructured composites of graphene with $\mathrm{CuO}$ which mostly involve either deposition of $\mathrm{CuO}$ nanoparticle on $\mathrm{GO}$ sheets followed by the reduction of GO or first to reduce GO sheets and then deposit or grow nanocrystals on the graphene sheets [18]. These methods often use toxic or hazardous reducing agents such as hydrazine [19], sodium borohydride, and ammonia [20] for GO reduction. Moderate-tosevere synthesis conditions including different unfavorable 
solvents or microwave energy under variable $\mathrm{pH}$, temperature, and pressures were employed. The most common methods for graphene/CuO synthesis include hydrothermal [15, 21, 22], sol-gel, microwave [17, 23, 24], sonochemical [25], and surfactant-assisted synthesis [26]. These methods need specific selection of appropriate synthesis conditions and suitable surfactants. Hence, there is a need to develop a greener, scalable, and facile route for the direct synthesis of nanostructured graphene/ $\mathrm{CuO}$ composites. So far, there is no report on direct solvent-free synthesis of in situ born $\mathrm{CuO}$ nanoparticles on reduced graphene oxides sheets without addition of toxic-reducing agent. Therefore, a cost-effective, environmentally friendly, and scalable production of nanostructured graphene/CuO composites can help to enhance ever-growing applications of such materials further. Herein, for the first time, the preparation of graphene/ $\mathrm{CuO}$ nanostructured composite via in situ process under mechano-thermal conditions using copper hydroxide and graphite oxide reagents is reported. No solvents, toxic-reducing agents, or surfactants are used. This simple and environmentally benign method is easily scalable for large scale production of high-quality graphene/CuO composite suitable for a wide range of applications.

Hydrogen sulfide $\left(\mathrm{H}_{2} \mathrm{~S}\right)$ is one of the most common and undesirable sulfur component often found in natural gas, syngas, biogas, and other industrial gases [27, 28]. Due of its high toxicity, offensive odor, and acidic nature, $\mathrm{H}_{2} \mathrm{~S}$ can pose serious threats to health and environment. Moreover, trace amount of $\mathrm{H}_{2} \mathrm{~S}$ can cause catalyst poisoning and pipeline corrosion [29]. Its oxidation in the atmosphere to $\mathrm{SO}_{2}$ results in an acid rain formation. Therefore, development of the new adsorbent materials with excellent desulfurization performance is critically needed. Owing to its thermal stability as well as favorable thermodynamics in sulfidization reaction, copper oxide is considered as a very effective metal oxide sorbent for the removal of $\mathrm{H}_{2} \mathrm{~S}$ from various gas streams [30, 31]. Additionally, copper-based sorbent does not suffer from metal volatility problems like other metallic sorbents. Copper oxide reacts with hydrogen sulfide to form the insoluble copper sulfide [32]. Hybridization of $\mathrm{H}_{2} \mathrm{~S}$ active $\mathrm{CuO}$ at nanoscale with high surface area support like graphene can further enhance the overall adsorption capacity of $\mathrm{H}_{2} \mathrm{~S}$. Thus, in this case, degree of oxygen functional groups and surface area of graphene in conjunction with particle size and distribution of metal oxide nanoparticles would be conducive for low-temperature $\mathrm{H}_{2} \mathrm{~S}$ adsorption [33]. Moreover, the graphene/CuO hybrid materials have not been explored as a sorbents for $\mathrm{H}_{2} \mathrm{~S}$ removal. Hence, in the present work, the effect of the sub- $20 \mathrm{~nm} \mathrm{CuO}$ supported onto high surface area graphene is investigated as a sorbent for $\mathrm{H}_{2} \mathrm{~S}$ removal.

\section{Experimental}

\subsection{Materials}

Graphite powder (Sigma-Aldrich, 10 mesh), sulfuric acid (Sigma-Aldrich, ACS reagent, 95.0-98.0\%), hydrochloric acid (Sigma-Aldrich, ACS reagent, $37 \%$ ), potassium permanganate (Fischer Scientific, $\geq 99 \%$ ), hydrogen peroxide (Sigma-Aldrich, $30 \mathrm{wt} \%$ in $\mathrm{H}_{2} \mathrm{O}$ ), sodium hydroxide (Sigma-Aldrich, ACS reagent, $\geq 97.0 \%$ ), copper nitrate dehydrate (Sigma-Aldrich, ACS reagent, $\geq 98 \%$ ), and phosphoric acid (Sigma-Aldrich, ACS reagent, $\geq 85 \mathrm{wt} \%$ in $\mathrm{H}_{2} \mathrm{O}$ ) were used. Copper hydroxide was prepared by procedure presented elsewhere [34].

\subsection{Synthesis of Graphite Oxide (GO)}

Graphite oxide was prepared from natural graphite by using improved synthesis proposed by Tour et al. [35]. In brief, the mixture of concentrated sulfuric acid $(270 \mathrm{~mL})$ and phosphoric acid $(33 \mathrm{~mL})$ was added to a 51 Erlenmeyer flask placed in an ice bath. About $5 \mathrm{~g}$ of natural flake graphite (10 mesh) was dispersed in the cold sulfuric acid with an overhead stirrer. Subsequently, $2.7 \mathrm{~g}$ of $\mathrm{KMnO}_{4}$ was added slowly over 1520 min, and the resulting one-pot mixture was stirred for $72 \mathrm{~h}$ at room temperature to allow the oxidation of graphite. The color of the mixture changed from dark purple-green to dark brown. Later, about $35 \%$ hydrogen peroxide $\left(\mathrm{H}_{2} \mathrm{O}_{2}\right)$ solution was added to terminate the oxidation process, and the color of the mixture changed to bright yellow, indicating a high oxidation level of graphite. The as-synthesized graphite oxide was suspended in water containing $1 \mathrm{M}$ dilute hydrochloric acid to obtain a yellow-brown dispersion, which was subjected to repeat washing with de-ionized water until a $\mathrm{pH}$ of 4-5 was achieved. To ensure complete removal of the residual salts and acids, dialysis process was used.

\subsection{Preparation of Graphene/CuO Nanohybrid (TRGC)}

Aqueous dispersions of GO $(200 \mathrm{mg})$ and stoichiometric quantity of copper hydroxide were prepared under ultrasonication for $30 \mathrm{~min}$ and rapidly mixed at room temperature in a round-bottomed flask followed by stirring. The resulting homogenous mixture was freeze-dried at $-90{ }^{\circ} \mathrm{C}$ to obtain $\mathrm{GO}-\mathrm{Cu}$ salt composite. Further, the composites were thermally annealed in a tube furnace at $400{ }^{\circ} \mathrm{C}$ for $2 \mathrm{~h}$ under argon atmosphere with a heating rate of $5{ }^{\circ} \mathrm{C} \mathrm{min}^{-1}$ to finally obtain graphene/CuO composite. A color change from light brown to black was also noticed. A stoichiometric quantity of copper hydroxide was used in order to 
obtain TRGC composite with $10 \mathrm{wt} \% \mathrm{CuO}$ loading. For comparison, thermally reduced graphene oxide (TRG) and copper oxide nanoparticles were synthesized under similar conditions and abbreviated as TRG and $\mathrm{CuO}$, respectively.

\subsection{Characterization}

The TRGC nanohybrid was characterized by X-ray diffraction (XRD), X-ray photoelectron spectroscopy (XPS), transmission electron microscopy (TEM), scanning electron microscopy (SEM), Raman spectroscopy, thermogravimetric analysis (TGA), and $\mathrm{N}_{2}$ physisorption. $\mathrm{XRD}$ was performed using $\mathrm{Cu} K \alpha$ radiation (X'Pert Pro $\mathrm{X}$-Ray diffractometer from Philips) at angle range (20/ $5-60^{\circ}$ ). The XPS measurements were performed on an SSX-100 system (Surface Science Laboratories, Inc.) equipped with a monochromated $\mathrm{Al} K_{\alpha} \mathrm{X}$-ray source, a hemispherical sector analyzer (HSA) and a resistive anode detector. TEM analysis was performed using FEI Tecnai G20 with $0.11 \mathrm{~nm}$ point resolution and operated at $200 \mathrm{kV}$ using Gatan digital camera. SEM (1540 XB Zeiss) coupled with energy-dispersive X-ray analysis (EDX) was used to determine the structure of the nanohybrids. LabRAM HR (Horiba Scientific) was used to obtain Raman spectra. Typically, a $50 \times$ objective was used with $633 \mathrm{~nm}$ excitation line. TGA was carried out by using Discovery TGA (TA instruments) in the temperature range from 50 to $800{ }^{\circ} \mathrm{C}$ at a ramp rate of $10{ }^{\circ} \mathrm{C}$ in an air atmosphere $\left(30 \mathrm{~mL} \mathrm{~min}{ }^{-1}\right) . \mathrm{N}_{2}$ physisorption was carried out at liquid $\mathrm{N}_{2}$ temperature with a Micromeritics ASPS 2010 analyzer to examine the porosity and surface area of the sample. The sample was pre-treated at $100{ }^{\circ} \mathrm{C}$ in a high vacuum for $24 \mathrm{~h}$ before $\mathrm{N}_{2}$ adsorption.

\section{$2.5 \mathrm{H}_{2} \mathrm{~S}$ Sorption Studies}

The $\mathrm{H}_{2} \mathrm{~S}$ sorption experiments were carried out at room temperature $\left(30{ }^{\circ} \mathrm{C}\right)$ and 290 psig pressure. The sorption tube was made of glass with an outer diameter of $8 \mathrm{~mm}$ and the height of $20 \mathrm{~mm}$, into which $\sim 0.5 \mathrm{~g}$ of the adsorbent was packed (Fig. 1). For adsorption, a model gas mixture containing (99.4\% of $\mathrm{CH}_{4}, 0.41 \%$ of $\mathrm{CO}_{2}$, and $0.15 \%$ of $\mathrm{H}_{2} \mathrm{~S}$ ) was passed through the adsorption cell with a flow rate of $40 \mathrm{~mL} \mathrm{~min}{ }^{-1}$. The gas mixture was delivered through the books mass flow controller at fixed flow rate. The analysis of the breakthrough gas was performed using a quadrupole mass spectrometer. Helium was used as marker gas. The breakthrough and saturation capacity [denoted as Cap (BT), mmol g ${ }^{-1}$, STP] for $\mathrm{H}_{2} \mathrm{~S}$ was calculated according to the following equation [36]:

$\operatorname{Cap}(\mathrm{BT})=\frac{\mathrm{BT} \times \mathrm{FR} \times C_{\mathrm{H}_{2} \mathrm{~S}}^{\mathrm{in}} \times 10^{-6}}{V_{\mathrm{mol}} \times W}$,

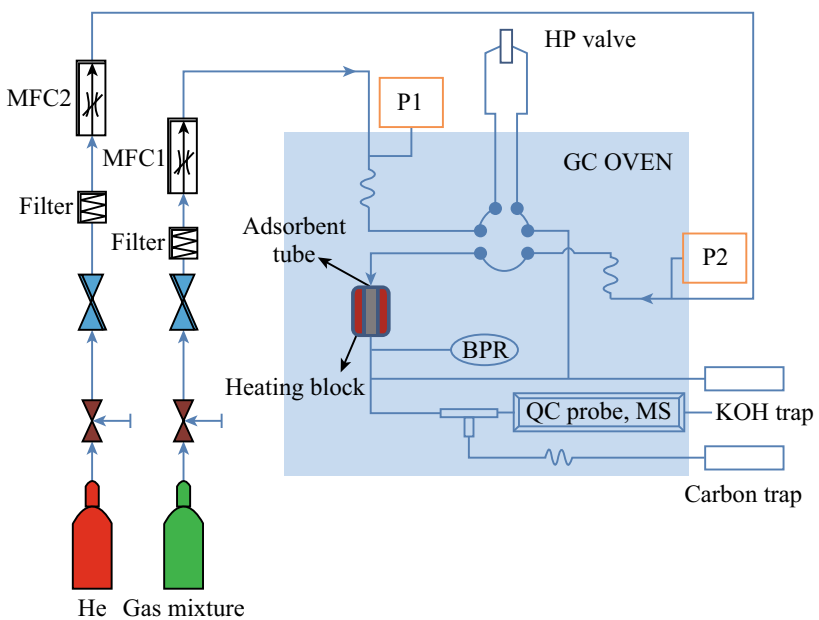

Fig. 1 Schematic of the fixed-bed flow system for $\mathrm{H}_{2} \mathrm{~S}$ adsorption measurements

where BT is the breakthrough time, the time (min) when the $\mathrm{H}_{2} \mathrm{~S}$ concentration reached $1 \%$ (i.e., $15 \mathrm{ppmv}$ ), $\mathrm{FR}$ is the flow rate $\left(\mathrm{mL} \mathrm{min}^{-1}\right), V_{\text {mol }}$ is the molar volume (24.4 $\mathrm{mL} \mathrm{mol}^{-1}$ at STP), $W$ is the weight of the sorbent (in grams), and $C_{\mathrm{H}_{2} \mathrm{~S}}^{\mathrm{in}}$ is the initial concentration of the $\mathrm{H}_{2} \mathrm{~S}$ in test gas mixture, respectively.

\section{Results and Discussion}

\subsection{Morphology and Structural Characterization}

TEM images of $\mathrm{CuO}$ nanoparticles and TRGC composite are shown in Fig. 2. Thermal annealing of $\mathrm{Cu}(\mathrm{OH})_{2}$ under controlled conditions resulted into egg-shaped $\mathrm{CuO}$ nanoparticles with average size below $100 \mathrm{~nm}$. A substantial decrease in the size of $\mathrm{CuO}$ particles (sub-20 nm) was noted in the presence of graphene which confirmed graphene's control on the size and dispersion of the $\mathrm{CuO}$ seeds. Moreover, $\mathrm{CuO}$ nanoparticles were observed to be uniformly dispersed on the surface of graphene. Thus, the TEM images revealed that the nanostructured TRGC composites with a uniform $\mathrm{CuO}$ dispersion were successfully prepared.

The structural features of the TRGC hybrid were elucidated using X-diffraction analysis. Figure 3 shows the XRD patterns of the $\mathrm{CuO}, \mathrm{GO}$, TRG, and TRGC hybrid. The XRD profile of GO exhibited characteristic peak at $9.7^{\circ}$ corresponding to the (001) plane of GO. After thermal exfoliation of GO to TRG, the diffraction peak at $9.7^{\circ}$ disappeared and a new broad peak at $25.9^{\circ}$ was observed, which corresponded to the graphene (002) planes. The XRD pattern of $\mathrm{CuO}$ indicated the characteristic diffraction peaks primarily indexed to a monoclinic structure (JCPDS 

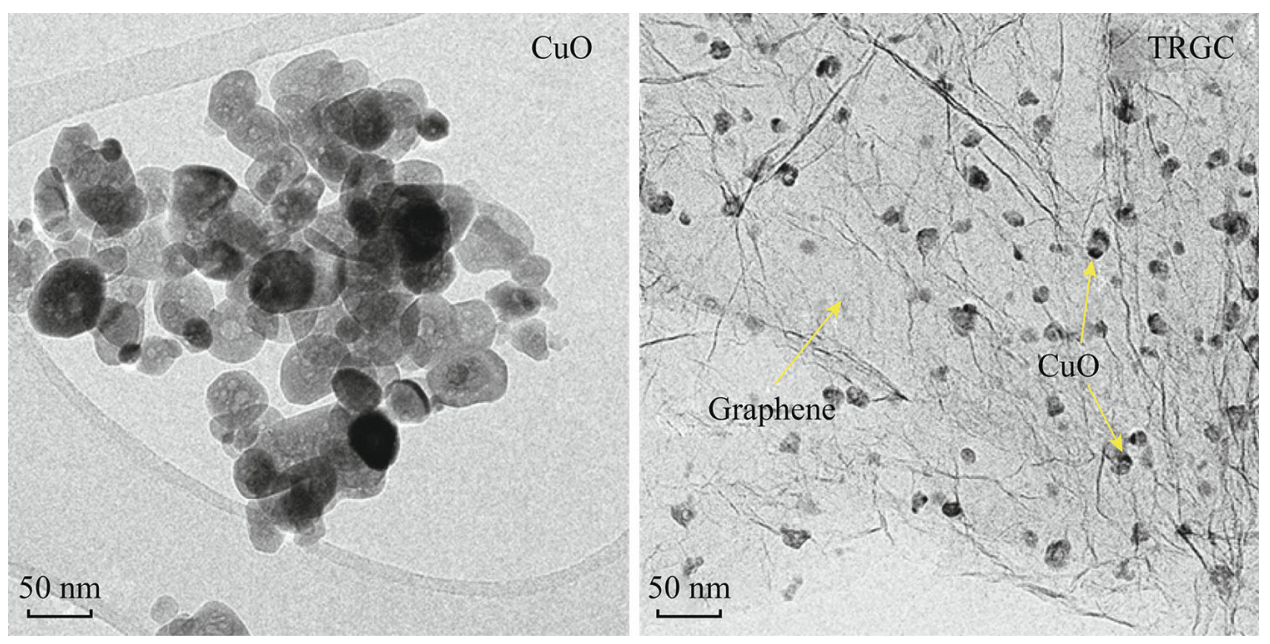

Fig. 2 TEM images of $\mathrm{CuO}$ nanoparticles and TRGC composite

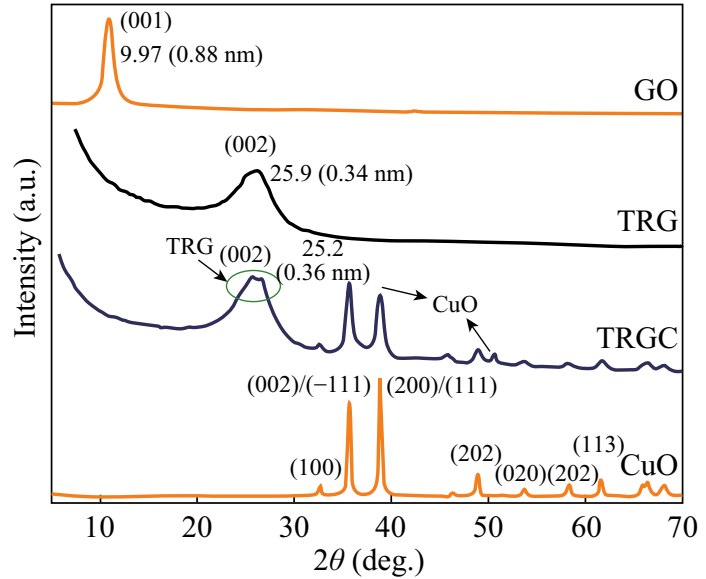

Fig. 3 XRD diffractograms of GO, CuO, TRG, and TRGC

No. 96-410-5686). For TRGC hybrid, the diffraction pattern exhibited the presence of diffraction peaks from $\mathrm{CuO}$ nanoparticles and a new broad peak at $2 \theta=24.33^{\circ}$ corresponding to the (002) peak of thermally reduced graphite oxide [37]. Moreover, a (002) diffraction peak broadening and a shift toward lower $2 \theta$ values compared to the asprepared pristine TRG signified the intercalation of $\mathrm{CuO}$ nanoparticles into TRG layers. In addition, no characteristic peaks corresponding to graphite oxide (the characteristic peak at around $2 \theta 9.7^{\circ}$ ) were observed in TRGC composite, indicating the successful thermal reduction of the layered GO in the composite. Hence, XRD revealed that the TRGC synthesis process involved the simultaneous thermal reduction of GO to TRG and in situ $\mathrm{CuO}$ nanoparticles formation.

XPS was used to trace the variations in surface composition after thermal reduction of GO and its interaction with in situ formed $\mathrm{CuO}$ nano-assemblies. Figure $4 \mathrm{a}$ shows the $\mathrm{C} 1 s$ and $\mathrm{O} 1 s$ chemical states of TRGC hybrid. The survey spectrum also shows the characteristic peaks of $\mathrm{Cu} 2 p$ and peaks of other elements were absent which ensured the contamination free in situ growth of $\mathrm{CuO}$ nanoassemblies on TRG sheets. The high-resolution scan of $\mathrm{Cu}$ $2 p$, as shown in Fig. 4a (inset), identified the exact peak location of $\mathrm{Cu} 2 p_{3 / 2}$ at $933.1 \mathrm{eV}$. Hence, successful formation graphene/ $\mathrm{CuO}$ nanohybrid under one-step thermoannealed process was further conformed. The structural features of the TRGC composite were further elucidated by Raman spectroscopy. Generally, graphitic materials show the characteristic $D$ and $G$ bands corresponding to k-point phonons of $A_{1 \mathrm{~g}}$ symmetry and $E_{2 \mathrm{~g}}$ phonon of $s p^{2}$ carbon which are assigned to local defects and disorder especially at the edges of graphene and graphite platelets [38, 39]. Figure $4 \mathrm{~b}$ shows the Raman spectra of the GO, TRG, and the corresponding TRGC hybrid. The pristine GO exhibited $G$ and $D$ bands at Raman shifts of 1580 and $1332 \mathrm{~cm}^{-1}$, respectively, with an intensity ratio, $I_{\mathrm{D}} / I_{\mathrm{G}}=0.97$. These two bands shifted to 1592 and $1349 \mathrm{~cm}^{-1}$ after the thermal treatment of GO. Such shifting is attributed due to the significant conversion of $s p^{3}$ to $s p^{2}$ carbon after thermal reduction. Also, trivial increase in $I_{\mathrm{D}} / I_{\mathrm{G}}$ to 1.21 was observed which indicated a decrease in the size of the inplane $s p^{2}$ domains, which was mainly attributed to the removal of the oxygen functional group in GO during thermal reduction process [40]. For TRGC composite, further increase in $I_{\mathrm{D}} / I_{\mathrm{G}}=1.63$ ratio was observed which signified the simultaneous $\mathrm{GO}$ reduction and $\mathrm{CuO}$ nanoparticle formation implying successful synthesis of TRGC hybrid.

The thermal stability and the composition of the TRGC nanocomposite were further investigated by using TGA in air atmosphere. Figure $4 \mathrm{c}$ shows the thermal behavior of the TRGC nanocomposite and TRG, GO, and $\mathrm{CuO}$ 

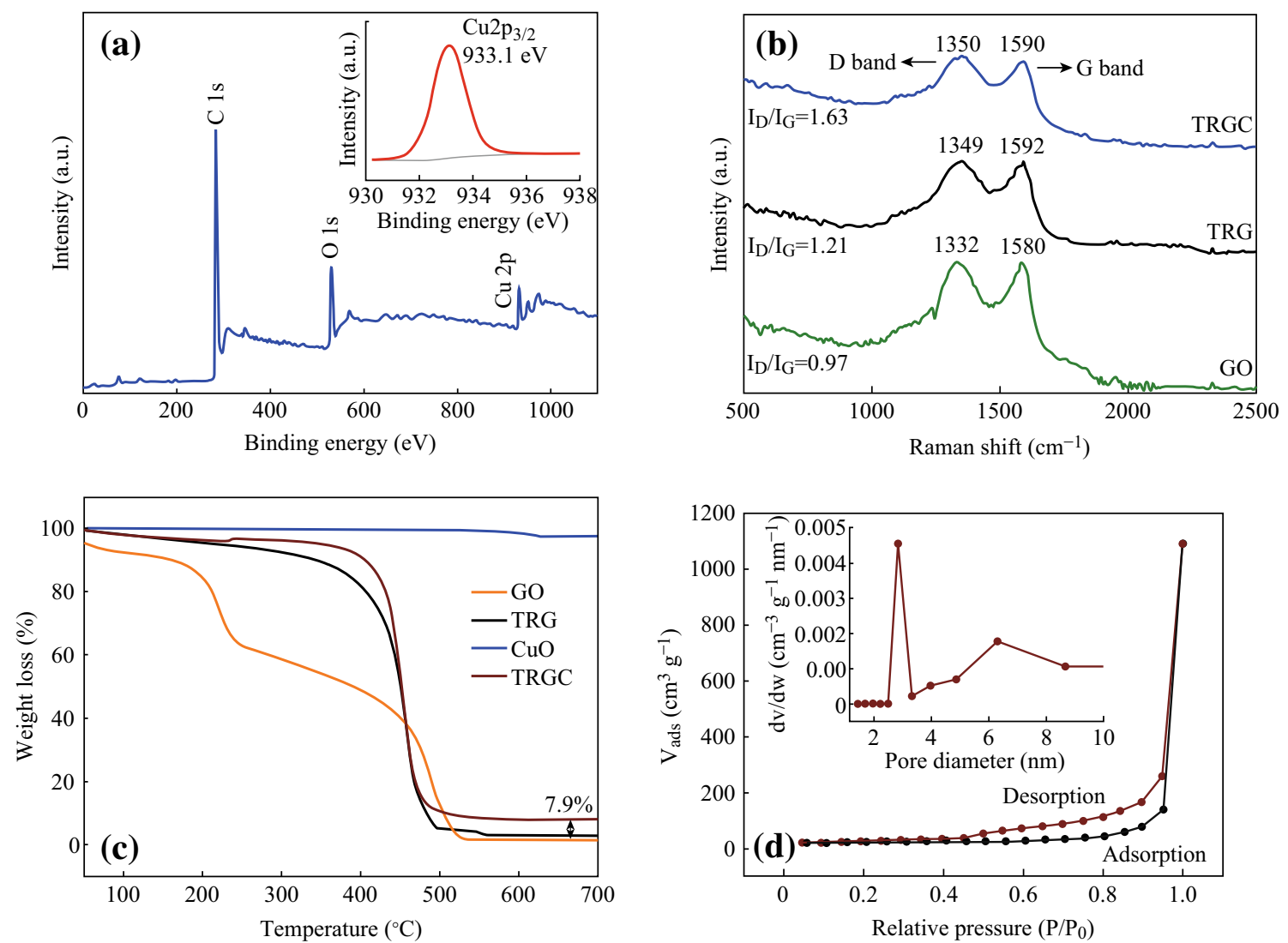

Fig. 4 a XPS survey spectrum of TRGC (inset deconvolution of $\mathrm{Cu} 2 \mathrm{P} 2$ ), b Raman spectra of GO, TRG, and TRGC nanohybrid, $\mathbf{c}$ TGA curves of GO, TRG, CuO NPs, and TRGC composite, and $\mathbf{d} \mathrm{N}_{2}$ adsorption-desorption isotherm and BJH pore size distribution plot (inset) of TRGC nanohybrid

nanoparticles, respectively. TGA curve of GO indicated two main weight loss steps, the first of which at around $100-250{ }^{\circ} \mathrm{C}$ was attributed to the decomposition of oxygen-containing functional groups on $\mathrm{GO}$ to $\mathrm{CO}, \mathrm{CO}_{2}$, and $\mathrm{H}_{2} \mathrm{O}$. The second degradation at around $400-600{ }^{\circ} \mathrm{C}$ was from the thermal decomposition of the GO structure. On the other hand, TRG thermogram indicated only one weight loss step. Slow decrease in weight between room temperature and $400{ }^{\circ} \mathrm{C}$ was attributed to the loss of surface bound water $\left(50-250^{\circ} \mathrm{C}\right)$ and the detachment of the oxygen functional groups (starting at $250{ }^{\circ} \mathrm{C}$ ). It was followed by accelerated weight loss between 400 and $500{ }^{\circ} \mathrm{C}$ due to the oxidative degradation of the graphene carbon framework in addition to the removal of residual oxygen functionalities. The deposition of $\mathrm{CuO}$ nanoparticles on the surface of TRG exhibited similar degradation profile as TRG with enhancement in the onset of weight loss probably due to the protective layer of $\mathrm{CuO}$ preventing oxidative degradation of TRG. The $\mathrm{CuO}$ nanoparticles exhibited high thermal stability, with almost no obvious mass loss up to $700{ }^{\circ} \mathrm{C}$. The final weight percentage of $\mathrm{CuO}$ in TRGC composite was measured to be at $7.9 \mathrm{wt} \%$. Further, specific surface area and the pore size distributions of the as-prepared TRG and TRGC were measured using the BET and BJH methods (Fig. 4d). TRGC exhibited type IV isotherm with $\mathrm{H} 1$ and $\mathrm{H} 2$ hysteresis loops. The hysteresis loop in the relative pressure $\left(p / p_{0}\right)$ range of $0.4-0.9$ is the characteristic of mesoporous materials.

The measured BET surface area of TRGC was $385 \mathrm{~m}^{2} \mathrm{~g}^{-1}$, which was higher than that of the as-prepared TRG $\left(305 \mathrm{~m}^{2} \mathrm{~g}^{-1}\right)$ suggesting that the in situ generation of $\mathrm{CuO}$ NPs effectively prevented overlap and coalescence of the graphene sheets. Moreover, the pore size of the TRGC was mainly distributed from 2.5 to $3.5 \mathrm{~nm}$ (Fig. 4d inset), which confirmed the nano-porous nature of the hybrid material.

\section{2 $\mathrm{H}_{2} \mathrm{~S}$ Adsorption Breakthrough Tests}

TRGC-nanostructured hybrid was evaluated for removal of $\mathrm{H}_{2} \mathrm{~S}$ at room temperature $\left(30^{\circ} \mathrm{C}\right)$ in the presence of $\mathrm{CO}_{2}$ and $\mathrm{CH}_{4}$. A dynamic $\mathrm{H}_{2} \mathrm{~S}$ breakthrough test was used 


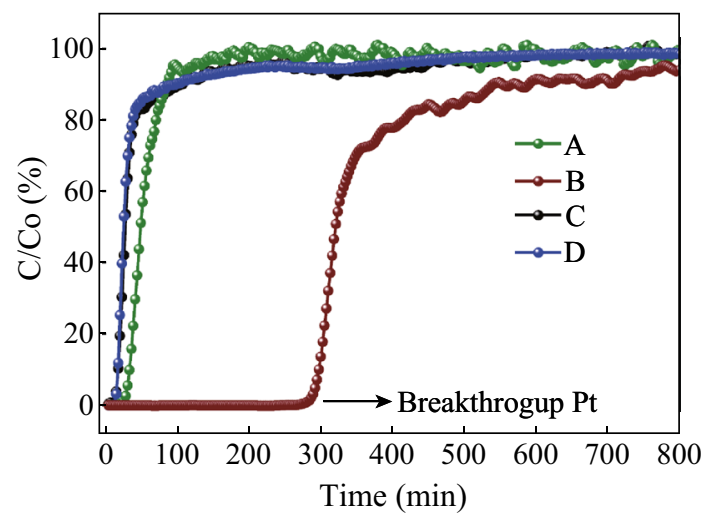

Fig. $5 \mathrm{H}_{2} \mathrm{~S}$ breakthrough curves for TRG (a), TRGC (b), $\mathrm{CH}_{4}$ and $\mathrm{CO}_{2}$ breakthrough curves for TRGC (c and d)

(Fig. 1) and the resulting breakthrough curves for tested adsorbents are shown in Fig. 5. Firstly, to gain insights about the contribution of $\mathrm{CH}_{4}$ sorption on the material, $\mathrm{CH}_{4}$ breakthrough curve of TRGC was measured under the same conditions mentioned above (Fig. 5). Saturation of the sorbent bed was completed in only $10 \mathrm{~min}$, which indicated that $\mathrm{CH}_{4}$ adsorption on the adsorbent was negligible. Pure TRG exhibited negligible breakthrough capacity at $0.06 \mathrm{mmol} \mathrm{H}_{2} \mathrm{~S} / \mathrm{g}$-sorbent and sulfur capacity of $30 \mathrm{mg} \mathrm{S} / 100 \mathrm{~g}$-sorbent due to the absence of any active sites. Remarkable difference in $\mathrm{H}_{2} \mathrm{~S}$ breakthrough curves was observed for the TRGC hybrid composite in comparison with pristine graphene. TRGC sorbent exhibited $\mathrm{H}_{2} \mathrm{~S}$ breakthrough point after $270 \mathrm{~min}$ which corresponded to the breakthrough capacity of $1.5 \mathrm{mmol} \mathrm{H}_{2} \mathrm{~S} / \mathrm{g}$-sorb and sulfur capacity $3 \mathrm{~g} \mathrm{~S} / 100 \mathrm{~g}$-sorbent. The obtained capacities were significantly higher than pristine $\mathrm{CuO}$ sorbent $\left(0.5 \mathrm{mmol} / \mathrm{H}_{2} \mathrm{~S} / \mathrm{g}\right.$-sorb $)$ and other CuO-based sorbents studied under nearly identical conditions [41, 42]. Moreover, it is to be noted that the observed capacity value was for $\mathrm{CuO}$ loading at $7.9 \mathrm{wt} \%$ which is considerably lesser amount of the active component compared with other copper oxide-based desulfurization sorbents [43-45]. Also, the TRGC sorbent did not show any reactivity with $\mathrm{CO}_{2}$.

The high $\mathrm{H}_{2} \mathrm{~S}$ sorption capacity for TRGC sorbent is attributed due to the sub- $20 \mathrm{~nm} \mathrm{CuO}$ particles which

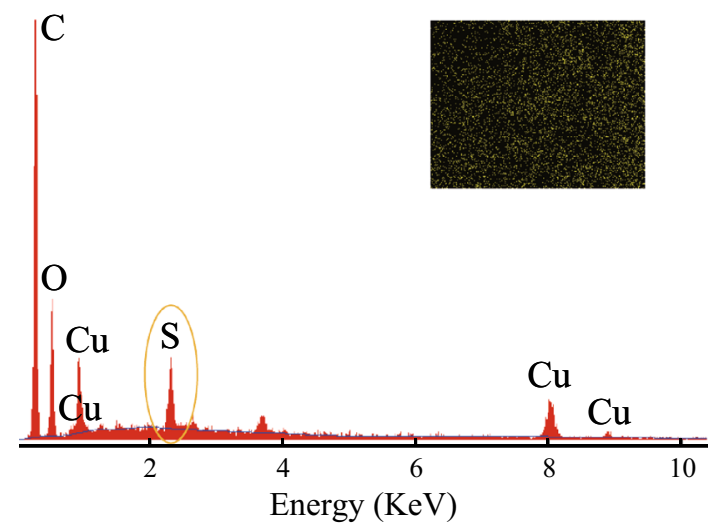

Fig. 7 EDX spectra of TRGC and sulfur elemental mapping (inset) after $\mathrm{H}_{2} \mathrm{~S}$ adsorption

enhanced the reactivity with $\mathrm{H}_{2} \mathrm{~S}$ at low temperature in conjunction with the high surface area of TRG which supported more active sites, i.e., finely distributed $\mathrm{CuO}$ nanoparticles. As mentioned earlier, the nanosized grains can enhance the reactivity with $\mathrm{H}_{2} \mathrm{~S}$ at low temperature and high surface areas can provide more active sites. Both properties are highly beneficial in improving the overall desulfurization performance of the sorbent [46]. The highly specific reaction of nanosized $\mathrm{CuO}$ toward $\mathrm{H}_{2} \mathrm{~S}$ even under oxygen-depleted environment is the formation of $\mathrm{CuS}$ [47]. Further, the residual oxygen-containing functional groups on the basal planes of TRG (as confirmed by XPS) played a critical role in promoting oxygen activation by accelerating the electron transfer, thereby promoting the activity of the terminal groups in surface reaction [48]. In addition, these functional groups helped the distribution of active $\mathrm{CuO}$ particles on the surface. So, the possible mechanism involves the initial physisorption of $\mathrm{H}_{2} \mathrm{~S}$ molecules by oxygenated functional groups on the graphene surface (Fig. 6a) which later reach to the finely dispersed active $\mathrm{CuO}$ nanoparticles and get chemisorbed through reactive adsorption and converted into $\mathrm{CuS}$ (Fig. 6b) [49]. In present work, sorbent TRGC had a considerably large surface area $\left(385 \mathrm{~m}^{2} \mathrm{~g}^{-1}\right)$, which was almost 10 times that of $\mathrm{CuO}$. Moreover, the pore volume of TRGC $\left(1.6 \mathrm{~cm}^{3} \mathrm{~g}^{-1}\right)$ was higher than that of $\mathrm{CuO}\left(0.083 \mathrm{~cm}^{3} \mathrm{~g}^{-1}\right)$. These parameters

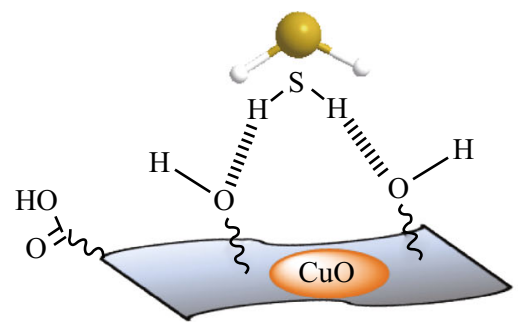

(a)

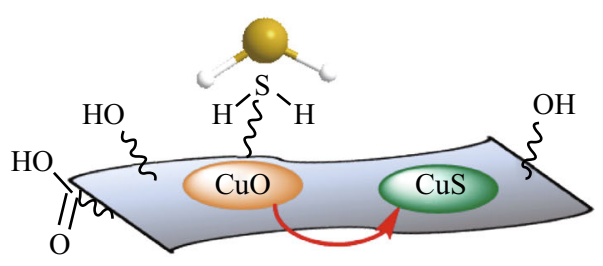

(b)

Fig. 6 Schematic representation for possible $\mathrm{H}_{2} \mathrm{~S}$ adsorption on TRGZ sorbent 
also helped to synergistically enhance the $\mathrm{H}_{2} \mathrm{~S}$ adsorption capacity of the TRGC adsorbent.

Further, the EDX spectra of $\mathrm{H}_{2} \mathrm{~S}$-treated TRGC composites were recorded to monitor the changes in elemental composition (Fig. 7). Strong peak for sulfur element was observed indicating the reactive adsorption of $\mathrm{H}_{2} \mathrm{~S}$ on the sorbent. The quantitative results of the $\mathrm{S} / \mathrm{Cu}$ ratio were calculated from the area of the corresponding spectral $K$ lines, and the amount of $\mathrm{S}$ in the composites was observed to be $\sim 10 \mathrm{wt} \%$ which was in agreement with the breakthrough calculations. The inset sulfur element mapping image also confirmed the reactivity of the uniformly dispersed reactive $\mathrm{CuO}$. However, to further elaborate this study, it would be important to investigate the reactivity of these adsorbents at higher temperatures, which is under investigation.

\section{Conclusions}

In summary, a facile one-pot method for the synthesis of a graphene/CuO (TRGC) nanocomposite based on in situ thermal reduction of $\mathrm{GO}$ and simultaneous $\mathrm{CuO}$ nanoparticle synthesis is reported. Sub-20 nm $\mathrm{CuO}$ nanoparticles could be homogeneously dispersed on the surface of graphene platelets, which ensured the high-sulfur sorption capacity at ambient temperatures and at lower $\mathrm{CuO}$ loading. The as-prepared TRGC nanocomposite, generated by greener and efficient synthesis method, holds significant promise for potential applications in environment and energy sectors.

Open Access This article is distributed under the terms of the Creative Commons Attribution 4.0 International License (http://crea tivecommons.org/licenses/by/4.0/), which permits unrestricted use, distribution, and reproduction in any medium, provided you give appropriate credit to the original author(s) and the source, provide a link to the Creative Commons license, and indicate if changes were made.

\section{References}

1. W.I. Park, C.-H. Lee, J.M. Lee, N.-J. Kim, G.-C. Yi, Inorganic nanostructures grown on graphene layers. Nanoscale 3(9), 3522-3533 (2011). doi:10.1039/c1nr10370a

2. Z. Tao, Y. Huang, X. Liu, J. Chen, W. Lei et al., High-performance photo-modulated thin-film transistor based on quantum dots/reduced graphene oxide fragmentsdecorated $\mathrm{ZnO}$ nanowires. Nano-Micro Lett. In Press. doi:10.1007/s40820-016-0083-7

3. J. Zhu, M. Chen, Q. He, L. Shao, S. Wei, Z. Guo, An overview of the engineered graphene nanostructures and nanocomposites. RSC Adv. 3(45), 22790-22824 (2013). doi:10.1039/c3ra44621b

4. S. Bai, X. Shen, Graphene-inorganic nanocomposites. RSC Adv. 2(1), 64 (2012). doi:10.1039/c1ra00260k

5. M. Sun, H. Liu, Y. Liu, J. Qu, J. Li, Graphene-based transition metal oxide nanocomposites for the oxygen reduction reaction. Nanoscale 7(4), 1250-1269 (2015). doi:10.1039/c4nr05838k
6. Q. Li, N. Mahmood, J. Zhu, Y. Hou, S. Sun, Graphene and its composites with nanoparticles for electrochemical energy applications. Nano Today 9(5), 668-683 (2014). doi:10.1016/j.nantod. 2014.09.002

7. Y. Zhu, S. Murali, W. Cai, X. Li, J.W. Suk, J.R. Potts, R.S. Ruoff, Graphene and graphene oxide: synthesis, properties, and applications. Adv. Mater. 22(35), 3906 (2010). doi:10.1002/adma. 201001068

8. Q.B. Zhang, K.L. Zhang, D.G. Xu, G.C. Yang, H. Huang, F.D. Nie, C.M. Liu, S.H. Yang, CuO nanostructures: synthesis, characterization, growth mechanisms, fundamental properties, and applications. Prog. Mater. Sci. 60(1), 208-337 (2014). doi:10. 1016/j.pmatsci.2013.09.003

9. M.H. Lee, K.T. Kim, T. Gemming, D.J. Sordelet, J. Eckert, Enhanced gas adsorption property of hybrid nanopore-structured copper oxide synthesized from the carbon nanotube/copper composites. J. Appl. Phys. 108(6), 064303 (2010). doi:10.1063/1. 3481431

10. C.C. Vidyasagar, Y. Arthoba Naik, T.G. Venkatesha, R. Viswanatha, Solid-State synthesis and effect of temperature on optical properties of $\mathrm{CuO}$ nanoparticles. Nano-Micro Lett. 4(2), 73-77 (2012). doi:10.3786/nml.v4i2.p73-77

11. D.M.A. Raj, A.D. Raj, A.A. Irudayaraj, Facile synthesis of rice shaped $\mathrm{CuO}$ nanostructures for battery application. J. Mater. SciMater. Electron. 25(3), 1441-1445 (2014). doi:10.1007/s10854014-1748-y

12. E. Mohammadi-Manesh, M. Vaezzadeh, M. Saeidi, $\mathrm{Cu}-$ and $\mathrm{CuO}$-decorated graphene as a nanosensor for $\mathrm{H}_{2} \mathrm{~S}$ detection at room temperature. Surf. Sci. 636, 36-41 (2015). doi:10.1016/j. susc.2015.02.002

13. K. Ramachandran, K.J. Babu, G.G. Kumar, A.R. Kim, D.J. Yoo, One-pot synthesis of graphene supported $\mathrm{CuO}$ nanorods for the electrochemical hydrazine sensor applications. Sci. Adv. Mater. 7(2), 329-336 (2015). doi:10.1166/sam.2015.2025

14. L.L. Cheng, Y.J. Wang, D.H. Huang, T. Nguyen, Y. Jiang, H.C. Yu, N. Ding, G.J. Ding, Z. Jiao, Facile synthesis of size-tunable $\mathrm{CuO} /$ graphene composites and their high photocatalytic performance. Mater. Res. Bull. 61, 409-414 (2015). doi:10.1016/j. materresbull.2014.10.036

15. N. Yusoff, N.M. Huang, M.R. Muhamad, S.V. Kumar, H.N. Lim, I. Harrison, Hydrothermal synthesis of $\mathrm{CuO}$ /functionalized graphene nanocomposites for dye degradation. Mater. Lett. 93(1), 393-396 (2013). doi:10.1016/j.matlet.2012.10.015

16. S.D. Seo, D.H. Lee, J.C. Kim, G.H. Lee, D.W. Kim, Roomtemperature synthesis of $\mathrm{CuO} /$ graphene nanocomposite electrodes for high lithium storage capacity. Ceram. Int. 39(2), 1749-1755 (2013). doi:10.1016/j.ceramint.2012.08.021

17. A.K. Rai, L.T. Anh, J. Gim, V. Mathew, J. Kang, B.J. Paul, N.K. Singh, J. Song, J. Kim, Facile approach to synthesize $\mathrm{CuO} / \mathrm{re}-$ duced graphene oxide nanocomposite as anode materials for lithium-ion battery. J. Power Sources 244(4), 435-441 (2013). doi:10.1016/j.jpowsour.2012.11.112

18. D.F. Qiu, B. Zhao, Z.X. Lin, L. Pu, L.J. Pan, Y. Shi, In situ growth of $\mathrm{CuO}$ nanoparticles on graphene matrix as anode material for lithium-ion batteries. Mater. Lett. 105(7), 242-245 (2013). doi:10.1016/j.matlet.2013.04.030

19. Y.J. Mai, X.L. Wang, J.Y. Xiang, Y.Q. Qiao, D. Zhang, C.D. Gu, J.P. Tu, CuO/graphene composite as anode materials for lithiumion batteries. Electrochim. Acta 56(5), 2306-2311 (2011). doi:10. 1016/j.electacta.2010.11.036

20. Y. Zhao, X. Song, Q. Song, Z. Yin, A facile route to the synthesis copper oxide/reduced graphene oxide nanocomposites and electrochemical detection of catechol organic pollutant. CrystEngComm 14(20), 6710-6719 (2012). doi:10.1039/c2ce25509j

21. K.K. Purushothaman, B. Saravanakumar, I.M. Babu, B. Sethuraman, G. Muralidharan, Nanostructured $\mathrm{CuO} /$ reduced graphene 
oxide composite for hybrid supercapacitors. RSC Adv. 4(45), 23485-23491 (2014). doi:10.1039/C4ra02107j

22. Q. Wang, J. Zhao, W.F. Shan, X.B. Xia, L.L. Xing, X.Y. Xue, $\mathrm{CuO}$ nanorods/graphene nanocomposites for high-performance lithium-ion battery anodes. J. Alloy. Compd. 590(2), 424-427 (2014). doi:10.1016/j.jallcom.2013.12.083

23. X.Y. Zhou, J.J. Shi, Y. Liu, Q.M. Su, J. Zhang, G.H. Du, Microwave-assisted synthesis of hollow $\mathrm{CuO}-\mathrm{Cu}_{2} \mathrm{O}$ nanosphere/graphene composite as anode for lithium-ion battery. J. Alloy. Compd. 615(2), 390-394 (2014). doi:10.1016/j.jallcom. 2014.07.013

24. X.Y. Zhou, J. Zhang, Q.M. Su, J.J. Shi, Y. Liu, G.H. Du, Nanoleaf-on-sheet $\mathrm{CuO}$ /graphene composites: microwave-assisted assemble and excellent electrochemical performances for lithium ion batteries. Electrochim. Acta 125, 615-621 (2014). doi:10.1016/j.electacta.2014.01.155

25. A. Pendashteh, M.F. Mousavi, M.S. Rahmanifar, Fabrication of anchored copper oxide nanoparticles on graphene oxide nanosheets via an electrostatic coprecipitation and its application as supercapacitor. Electrochim. Acta 88(2), 347-357 (2013). doi:10.1016/j.electacta.2012.10.088

26. T.T. Baby, R. Sundara, Synthesis and transport properties of metal oxide decorated graphene dispersed nanofluids. J. Phys. Chem. C 115(17), 8527-8533 (2011). doi:10.1021/Jp200273g

27. D. Panza, V. Belgiorno, Hydrogen sulphide removal from landfill gas. Process Saf. Environ. Prot. 88(6), 420-424 (2010). doi:10. 1016/j.psep.2010.07.003

28. L.C. Yang, X.M. Ge, C.X. Wan, F. Yu, Y.B. Li, Progress and perspectives in converting biogas to transportation fuels. Renew. Sust. Energy Rev. 40, 1133-1152 (2014). doi:10.1016/j.rser. 2014.08.008

29. W.R.P.J. Kidnay, D.G. McCartney, Fundamentals of Natural Gas Processing (CRC Press, Boca Raton, FL, 2011)

30. M. Xue, R. Chitrakar, K. Sakane, K. Ooi, Screening of adsorbents for removal of $\mathrm{H}_{2} \mathrm{~S}$ at room temperature. Green Chem. 5(5), 529-534 (2003). doi:10.1039/B303167p

31. C.L. Carnes, K.J. Klabunde, Unique chemical reactivities of nanocrystalline metal oxides toward hydrogen sulfide. Chem. Mater. 14(4), 1806-1811 (2002). doi:10.1021/Cm011588r

32. S. Yasyerli, G. Dogu, I. Ar, T. Dogu, Activities of copper oxide and $\mathrm{Cu}-\mathrm{V}$ and $\mathrm{Cu}-\mathrm{Mo}$ mixed oxides for $\mathrm{H}_{2} \mathrm{~S}$ removal in the presence and absence of hydrogen and predictions of a deactivation model. Ind. Eng. Chem. Res. 40(23), 5206-5214 (2001). doi:10.1021/Ie0010621

33. H.S. Song, M.G. Park, S.J. Kwon, K.B. Yi, E. Croiset, Z. Chen, S.C. Nam, Hydrogen sulfide adsorption on nano-sized zinc oxide/ reduced graphite oxide composite at ambient condition. Appl. Surf. Sci. 276(3), 646-652 (2013). doi:10.1016/j.apsusc.2013.03. 147

34. D.P. Singh, A.K. Ojha, O.N. Srivastava, Synthesis of different $\mathrm{Cu}(\mathrm{OH})(2)$ and $\mathrm{CuO}$ (nanowires, rectangles, seed-, belt-, and sheetlike) nanostructures by simple wet chemical route. J. Phys. Chem. C 113(9), 3409-3418 (2009). doi:10.1021/Jp804832g

35. D.C. Marcano, D.V. Kosynkin, J.M. Berlin, A. Sinitskii, Z.Z. Sun, A. Slesarev, L.B. Alemany, W. Lu, J.M. Tour, Improved synthesis of graphene oxide. ACS Nano 4(8), 4806-4814 (2010). doi: $10.1021 / \mathrm{Nn} 1006368$
36. X.X. Wang, X.L. Ma, X.C. Xu, L. Sun, C.S. Song, Mesoporousmolecular-sieve-supported polymer sorbents for removing $\mathrm{H}(2) \mathrm{S}$ from hydrogen gas streams. Top. Catal. 49(1-2), 108-117 (2008). doi:10.1007/s11244-008-9072-5

37. H.M. Ju, S.H. Choi, S.H. Huh, X-ray diffraction patterns of thermally-reduced graphenes. J. Korean Phys. Soc. 57(6), 1649 (2010). doi:10.3938/Jkps.57.1649

38. M. Cheng, R. Yang, L.C. Zhang, Z.W. Shi, W. Yang, D.M. Wang, G.B. Xie, D.X. Shi, G.Y. Zhang, Restoration of graphene from graphene oxide by defect repair. Carbon 50(7), 2581-2587 (2012). doi:10.1016/j.carbon.2012.02.016

39. D. Graf, F. Molitor, K. Ensslin, C. Stampfer, A. Jungen, C. Hierold, L. Wirtz, Spatially resolved raman spectroscopy of single- and few-layer graphene. Nano Lett. 7(2), 238-242 (2007). doi:10.1021/nl061702a

40. D. Zhan, Z.H. Ni, W. Chen, L. Sun, Z.Q. Luo, L.F. Lai, T. Yu, A.T.S. Wee, Z.X. Shen, Electronic structure of graphite oxide and thermally reduced graphite oxide. Carbon 49(4), 1362-1366 (2011). doi:10.1016/j.carbon.2010.12.002

41. O. Karvan, $\mathrm{H}$. Atakul, Investigation of $\mathrm{CuO}$ /mesoporous SBA-15 sorbents for hot gas desulfurization. Fuel Process. Technol. 89(9), 908-915 (2008). doi:10.1016/j.fuproc.2008.03.004

42. D. Liu, S. Chen, X. Fei, C. Huang, Y. Zhang, Regenerable CuObased adsorbents for low temperature desulfurization application. Ind. Eng. Chem. Res. 54(14), 3556-3562 (2015). doi:10.1021/ acs.iecr.5b00180

43. Y.K. Song, K.B. Lee, H.S. Lee, Y.W. Rhee, Reactivity of copper oxide-based sorbent in coal gas desulfurization. Korean J. Chem. Eng. 17(6), 691-695 (2000). doi:10.1007/Bf02699119

44. F. Li, J. Wei, Y. Yang, G.H. Yang, T. Lei, Preparation of sorbent loaded with nano-CuO for room temperature to remove of hydrogen sulfide. Appl. Mech. Mater. Sens. Meas. Intell. Mater. II(475-476), 1329-1333 (2014). doi:10.4028/www.scientific.net/ AMM.475-476.1329

45. D. Montes, E. Tocuyo, E. Gonzalez, D. Rodriguez, R. Solano, R. Atencio, M.A. Ramos, A. Moronta, Reactive $\mathrm{H}_{2} \mathrm{~S}$ chemisorption on mesoporous silica molecular sieve-supported $\mathrm{CuO}$ or $\mathrm{ZnO}$. Microporous Mesoporous. Mater. 168(168), 111-120 (2013). doi:10.1016/j.micromeso.2012.09.018

46. H.S. Song, M.G. Park, W. Ahn, S.N. Lim, K.B. Yi, E. Croiset, Z. Chen, S.C. Nam, Enhanced adsorption of hydrogen sulfide and regeneration ability on the composites of zinc oxide with reduced graphite oxide. Chem. Eng. J. 253(7), 264-273 (2014). doi:10. 1016/j.cej.2014.05.058

47. A. Galtayries, J.P. Bonnelle, XPS and ISS studies on the interaction of $\mathrm{H}_{2} \mathrm{~S}$ with polycrystalline $\mathrm{Cu}, \mathrm{Cu}_{2} \mathrm{O}$ and $\mathrm{CuO}$ surfaces. Surf. Interface Anal. 23(3), 171-179 (1995). doi:10.1002/sia. 740230308

48. M. Seredych, O. Mabayoje, T.J. Bandosz, Visible-light-enhanced interactions of hydrogen sulfide with composites of zinc (oxy)hydroxide with graphite oxide and graphene. Langmuir 28(2), 1337-1346 (2012). doi:10.1021/La204277c

49. O. Mabayoje, M. Seredych, T.J. Bandosz, Enhanced reactive adsorption of hydrogen sulfide on the composites of graphene/graphite oxide with copper (hydr)oxychlorides. ACS Appl. Mater. Inter. 4(6), 3316-3324 (2012). doi:10.1021/am300702a 